\title{
ACETABULAR RECONSTRUCTION IN PAPROSKY TYPE III DEFECTS
}

\section{RECONSTRUÇÃO ACETABULAR EM DEFEITOS POR PAPROSKY TIIPO III}

\author{
Jaime J.Morales De Cano $^{1}$, Llorenç Guillamet ${ }^{1}$, Arturo Perez Pons ${ }^{1}$ \\ 1. Hospital Universitario de Vic, Orthopaedic Surgery, Vic, Barcelona, Spain.
}

\section{ABSTRACT}

Objectives: Severe pelvic deficiency presents a difficult problem in hip arthroplasty. Specifically, the goals are to restore the pelvic bone stock, place the acetabular component in the correct anatomical position, and optimize joint stability. Currently, many surgical techniques have been developed for prosthetic revision surgery for acetabular complex defects, but no consensus has been reached on the best treatment. The objective of this study was to review mid-term cases of severe bone defect (Paprosky type III) treated with a bone allograft and ring Bursch-Schneider anti-protrusion cage (BSAC). Methods: A retrospective consecutive series review of the first 23 complex acetabular reconstructions performed between 2006 and 2011 was conducted. The series included the learning curve of the procedure and a minimum 5-year follow-up. Conclusion: Our study confirmed the efficacy of using a frozen morselized allograft combined with a metal ring-type BSAC for acetabular reconstruction. The anatomical location of the center of rotation of the hip must be recovered for long-term success. In massive loosening cases, the anatomical center of rotation can only be restored by bone density reconstruction using a graft protected by a ring to improve the centering of the head. Level of Evidence IV, Case Series.

Keywords: Joint revision, hip arthroplasty, bone graft, reconstructive surgical procedure

\section{RESUMO}

Objetivos: A deficiência pélvica severa apresenta um problema difícil na artroplastia do quadril. Especificamente, os objetivos são restaurar o estoque ósseo pélvico, colocar o componente acetabular na posição anatômica correta e otimizar a estabilidade da articulação. Atualmente, existem muitas técnicas cirúrgicas para a cirurgia de revisão protética em defeitos do complexo acetabular, mas não há consenso sobre o melhor tratamento. Os objetivos deste trabalho são revisar casos de médio prazo operados por apresentar defeito ósseo grave (Paprosky tipo III) tratado com aloenxerto ósseo e gaiola anelar Bursch - Schneider anti protusio (BSAC). Métodos: Foi realizada uma revisão retrospectiva consecutiva das primeiras 23 reconstruções acetabulares complexas realizadas entre 2006 e 2011. Esta série inclui a curva de aprendizado do procedimento e tem um acompanhamento mínimo de 5 anos. Conclusão: Em conclusão, nosso estudo confirma a eficácia do uso de aloenxerto morselado congelado combinado com um anel de metal tipo BSAC durante a reconstrução acetabular. É necessário recuperar o centro de rotação do quadril em sua localização anatômica para o sucesso a longo prazo. Em casos de soltura maciça, o centro anatómico de rotação só pode ser restaurado pela reconstrução da densidade óssea usando um enxerto protegido por um anel que melhora a centralização da cabeça. Nível de Evidência tipo IV, Série de Casos.

Descritores: Revisão articular, artroplastia do quadril, enxertos ósseos, procedimentos cirúrgicos reconstrutivos.

Citation: Morales de Cano JJ, Guillamet L, Perez Pons A. Acetabular reconstruction in paprosky type III defects. Acta Ortop Bras. [online]. 2019;27(1):5963. Available from URL: http://www.scielo.br/aob.

\section{INTRODUCTION}

In recent years it has been producing an increase the number of surgeries revision total hip arthroplasty (THA). This is because the indications for THAs are expanding include younger patients with more planned activity and demands. ${ }^{1}$ Charnley in 1979 suggested that revision prosthetic surgery would be the main cause of concern in the THA. Nowadays, THA loosening rates have been increasing so that doubled revision surgery each 10 years. $^{2}$

In prosthetic revision surgery, where a significant acetabular loss is there, must perform an acetabular reconstruction. The purpose of the acetabular reconstruction is to obtain a stable, permanent fixation of a new acetabular component to restore the center of rotation and, if possible restoring bone stock. During revision surgery simple acetabular defects, either cavitary or segmental, can be solved with conventional cementless THA (hemisferic acetabular components). However, combined segmental and cavitary defects are more difficult, especially those with no upper acetabular coverage. ${ }^{3,4}$ Currently there are many surgical techniques for prosthetic revision surgery in acetabular complex defects, but there is no consensus on the best treatment. The impacted bone graft is an attractive treatment option for restoring severe acetabular bone defects (Paprosky type III) in total revision of the THA; ${ }^{5}$ however, it requires the placement of a metal frame for attaching a primary stabilization. 6,7

The objectives of this paper is to review medium term cases operated by presenting a severe bone defect (Paprosky type III) treated with bone allograft and ring Bursch - Schneider ant protusio cage

\section{All authors declare no potential conflict of interest related to this article.}

Study was conducted at the Department of Orthopaedic Surgery, Hospital Universitario de Vic, Barcelona, Spain. Correspondence: Jaime J.Morales De Cano. Carrer de Francesc Pla el Vigatà, 1 Vic, Barcelona, Spain. 08500. 15449jmc@comb.cat 
(BSAC). This review technique is attractive because it addresses the three objectives of the acetabular reconstruction: providing a stable and lasting fixation for a new acetabulum, restore the center of rotation; and achieve the restoration of bone stock.

\section{METHODS AND MATERIALS}

A retrospective consecutive series review was undertaken of the first 23 complex acetabular reconstructions performed between 2006 and 2011 (Table 1). This series includes the learning curve of the procedure and has a minimum 5-year follow-up. All cases were performed by the senior author (JM), a consultant orthopaedic surgeon with an interest in revision hip arthroplasty surgery. All patients were operated using cancellous allograft bone crushed with BSAC and a cemented cup.

The average time between the initial total hip replacement (THA) and the revision acetabular surgery was 111 months (range, 12-228 months). Acetabular bone status was classified during the operation according to the criteria of Paprosky et al. $^{3}$ as Grade 3A (15 hips) and Grade 3B (8 hips). Different cemented (3 hips) and cementless (20 hips) THAs were revised in this series. Each revised cup was individually assessed; 16 (69,56\%) only underwent acetabular revision, whereas $7(30,44 \%)$ underwent revision of both components. In all cases where a revision was done, an uncemented stem was used (Conelock-Biomet).

The cohort included 10 men (43.47\%) and 13 women (56,52\%) with an average age at the time of revision surgery of 77.04 years (range, 68-88 years). The average number of procedures performed before the present acetabular revision was 1.78 (range, $1-3)$. Diagnosis at the time of cemented cage reconstruction was as follows: aseptic loosening/mechanical failure $(n=19)$, instability $(n=1)$, reimplant for infection $(n=3)$. Preoperative evaluation according to the scale of MD Score average was 6.6 (range 5-9). The surgical planning, in cases where a intrapelvic penetration of the acetabular loosened component existed, included performing a digital subtraction angiography (DSA) arteriogram, to locate the femoral artery (Figure 1). The primary objective was to restore the center of rotation of the hip.
All procedures were performed by the same surgeon, in supine position and using an anterolateral Watson-Jones aproach. The acetabular component was removed with the required extractional instrumentrs, preserving as much bone as possible. Cystic areas were aggressively debrided. Then, the acetabulum was inspected to identify osteolysis areas, determine the type of bone defects, and evaluate the presence of pelvic discontinuity. The acetabular bone bed was reamed with hemispherical reamers. Acetabular margins were defined, and the cup was always placed at the nearest of the center of rotation of the hip. In revision surgery with large bone defects, the obturator foramen is always a good reference for positioning the cup down and out. In all cases we use fresh frozen allograft femoral head, got in the bone bank. Bone was morselized with a bone mill, or manually using a rongeur. Then placed the BSAC ring, pinning the inner pin on the ischium and the other flange bolted to the ileum with 5 screws, checking its stability (Figure 2). Then put a cemented polyethylene cup size to the size of the corresponding ring.

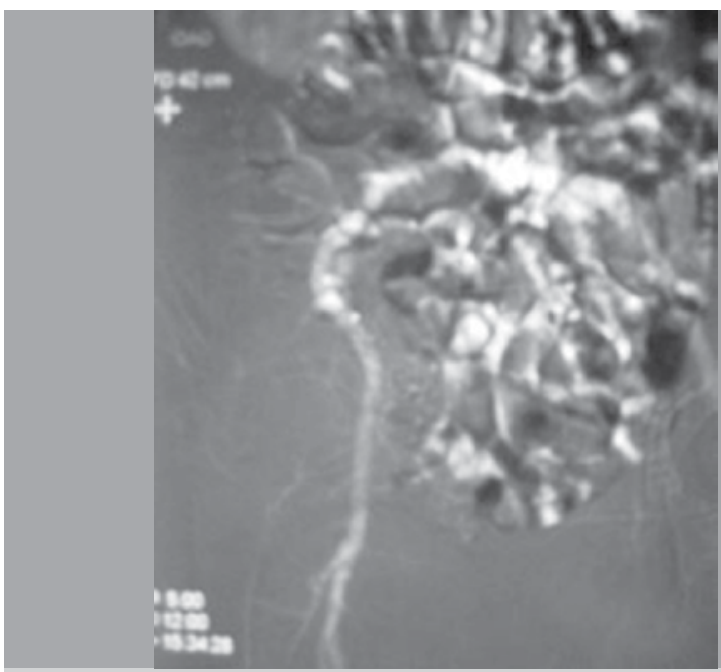

Figure 1. Digital subtraction angiography (DSA)

Table 1. Summary of the 23 consecutive acetabular impaction graftings performed by using impaction grafting of a defect that has been contained with a metallic Bursch-Schneider antiprotusio cage, followed by implantation of a cemented polyethylene cup.

\begin{tabular}{|c|c|c|c|c|c|c|c|c|c|c|c|c|}
\hline Case & Gender & Age & \begin{tabular}{|c|}
$\begin{array}{c}\text { Merle 'Aubigne } \\
\text { score }\end{array}$ \\
\end{tabular} & \begin{tabular}{|c|} 
Prior \\
surgeries
\end{tabular} & $\begin{array}{c}\text { Type acetabular } \\
\text { defect }\end{array}$ & Side & Intervencio & Graft type & \begin{tabular}{|c|} 
Type of \\
cage
\end{tabular} & $\begin{array}{c}\text { Concomitant } \\
\text { femoral revision }\end{array}$ & $\begin{array}{c}\begin{array}{c}\text { Merle D'Aubigne } \\
\text { score }\end{array} \\
\end{array}$ & $\begin{array}{l}\text { Follow-up } \\
\text { (months) }\end{array}$ \\
\hline & & & Preop. & & & & & & & & Postop. & \\
\hline 1 & $\mathrm{~F}$ & 74 & 6 & 2 & 3.A & $\mathrm{R}$ & SEPTIC & Fresh frozen & BSAG & Yes & 14 & 48 \\
\hline 2 & $\mathrm{~F}$ & 76 & 5 & 1 & $3 . A$ & $\mathrm{R}$ & Mechanical failure & Fresh frozen & BSAG & Yes & 16 & 51 \\
\hline 3 & $\mathrm{~F}$ & 79 & 7 & 1 & 3.B & $\mathrm{R}$ & Mechanical failure & Fresh frozen & BSAG & Yes & 17 & 60 \\
\hline 4 & $\mathrm{~F}$ & 82 & 6 & 3 & $3 . B$ & $\mathrm{R}$ & Mechanical failure & Fresh frozen & BSAG & Yes & 16 & 59 \\
\hline 5 & $\mathrm{~F}$ & 73 & 7 & 3 & $3 . A$ & $\mathrm{R}$ & Mechanical failure & Fresh frozen & BSAG & Yes & 16 & 56 \\
\hline 6 & $\mathrm{M}$ & 71 & 6 & 1 & $3 . \mathrm{A}$ & $\mathrm{R}$ & Mechanical failure & Fresh frozen & BSAG & No & 16 & 49 \\
\hline 7 & $M$ & 78 & 5 & 1 & 3.B & $\mathrm{R}$ & Mechanical failure & Fresh frozen & BSAG & Yes & 17 & 53 \\
\hline 8 & $M$ & 83 & 7 & 1 & $3 . \mathrm{A}$ & $\mathrm{R}$ & Mechanical failure & Fresh frozen & BSAG & No & 15 & 54 \\
\hline 9 & $\mathrm{M}$ & 85 & 8 & 2 & $3 . A$ & $\mathrm{R}$ & Instability & Fresh frozen & BSAG & No & 16 & 51 \\
\hline 10 & $M$ & 88 & 7 & 1 & 3.B & $\mathrm{R}$ & Mechanical failure & Fresh frozen & BSAG & No & 15 & 49 \\
\hline 11 & $M$ & 77 & 6 & 2 & $3 . B$ & $\mathrm{R}$ & Mechanical failure & Fresh frozen & BSAG & Yes & 17 & 48 \\
\hline 12 & $\mathrm{~F}$ & 68 & 6 & 2 & $3 . A$ & $\mathrm{~L}$ & RECANVI PTM ESQ. & Fresh frozen & BSAG & Yes & 16 & 58 \\
\hline 13 & $\mathrm{~F}$ & 69 & 8 & 1 & $3 . A$ & $\mathrm{~L}$ & Mechanical failure & Fresh frozen & BSAG & Yes & 17 & 54 \\
\hline 14 & $\mathrm{~F}$ & 75 & 7 & 1 & $3 . A$ & $\mathrm{~L}$ & Mechanical failure & Fresh frozen & BSAG & No & 15 & 52 \\
\hline 15 & $\mathrm{~F}$ & 76 & 6 & 3 & $3 . B$ & $\mathrm{~L}$ & Mechanical failure & Fresh frozen & BSAG & Yes & 16 & 49 \\
\hline 16 & $\mathrm{~F}$ & 77 & 7 & 1 & $3 . A$ & $\mathrm{~L}$ & Mechanical failure & Fresh frozen & BSAG & Yes & 17 & 48 \\
\hline 17 & $\mathrm{~F}$ & 77 & 7 & 2 & $3 . A$ & $\mathrm{~L}$ & Mechanical failure & Fresh frozen & BSAG & No & 16 & 55 \\
\hline 18 & $\mathrm{~F}$ & 82 & 6 & 2 & $3 . B$ & $\mathrm{~L}$ & SEPTIC & Fresh frozen & BSAG & Yes & 16 & 49 \\
\hline 19 & $\mathrm{~F}$ & 83 & 6 & 3 & $3 . A$ & $\mathrm{~L}$ & Mechanical failure & Fresh frozen & BSAG & Yes & 16 & 48 \\
\hline 20 & $\mathrm{M}$ & 72 & 6 & 3 & $3 . A$ & $\mathrm{~L}$ & Mechanical failure & Fresh frozen & BSAG & No & 17 & 54 \\
\hline 21 & $M$ & 73 & 7 & 2 & 3.B & $\mathrm{L}$ & Mechanical failure & Fresh frozen & BSAG & Yes & 15 & 55 \\
\hline 22 & $M$ & 75 & 8 & 1 & $3 . A$ & $\mathrm{~L}$ & Mechanical failure & Fresh frozen & BSAG & Yes & 16 & 52 \\
\hline 23 & $M$ & 79 & 9 & 2 & $3 . A$ & $\mathrm{~L}$ & SEPTIC & Fresh frozen & BSAG & Yes & 16 & 50 \\
\hline
\end{tabular}




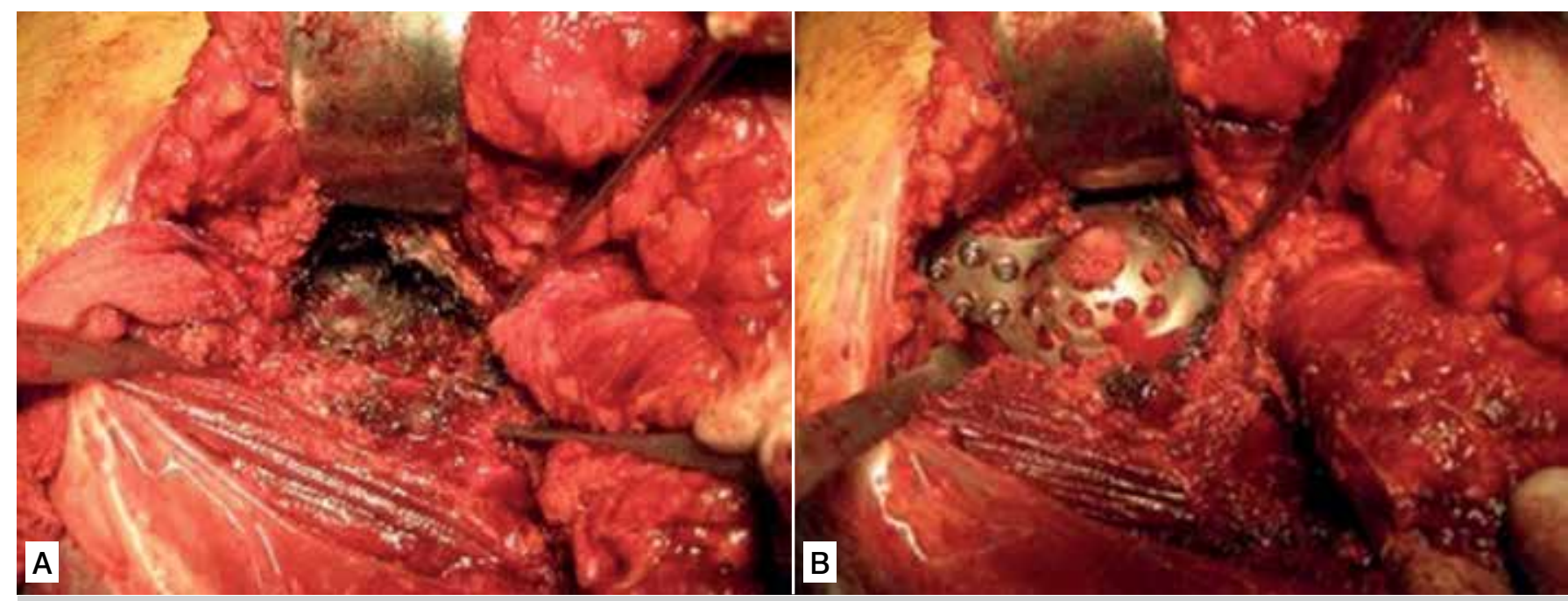

Figure 2. A) Extensive posterolateral acetabular exposure with massive bone loss. B) Reconstruction acetabular with a allograft and Bursch-Schneider antiprotusio cage.

In all cases, low-molecular-weight heparin was used as an anticoagulant during the first month after surgery, and $2 \mathrm{~g}$ of Cefazoline was used in the initial anesthesia in no septic revision. Following our normal hospital procedure, surgical bleeding was controlled with tranexamic acid. During the postoperative period, ambulatory re-education was carried out. Patients were evaluated clinically using the Merle d'Aubigne score (MD). Radiological assessment was carried out by means of a standard AP X-ray of the pelvis and lateral hip, checking for migration, osteolysis and signs of radiolucency in the three DeLee acetabular zones.

\section{RESULTS}

We had no intraoperative complications. In all cases has gotten a good stability in the rings anclage and acetabular components have been chosen. We had no infections nor vascular injuries or nerve complications. Postoperative prosthetic dislocation has been done in 4 cases (17.39\%), all were resolved with bloodless reduction. Mean blood of these patients was 650cc (300-800cc range), therefore we can say that they are bleeding interventions that have had to resort to transfusion in 14 cases $(60.86 \%)$. From the clinical point of view, the mean MD at the end of the follow-up was 16 points (range 14-17). At the final of the follow-up has not been any reoperation in these patients. The radiographic assessment does not demonstrate mobilization components, although the assessment of the incorporation of the grafts is difficult to assess because of the multitude of metallic artefact (Figure 3). No new intervention has been made during the follow-up of our series.

\section{DISCUSSION}

Our study has important limitations. This is a retrospective study done without a control group. Rather, the study was performed with a single observer, limiting how bias in interpreting results. This study supports our surgical approach and highlights the benefit of correctly position the center of rotation, which led us to use the ring BSAC.

The restitution of the lost bone stock is one of the biggest challenges of acetabulum revision surgery. Classification systems for the acetabular defect allow unification in the defect and can give guidelines for treatment. The AAOS classification system described by D'Antonio et al. ${ }^{9}$ grades the acetabular defect in five types: segmental, cavitary or combined deficiencies, pelvic discontinuity, and arthrodesis. The Paprosky classification system ${ }^{3}$ stratifies the

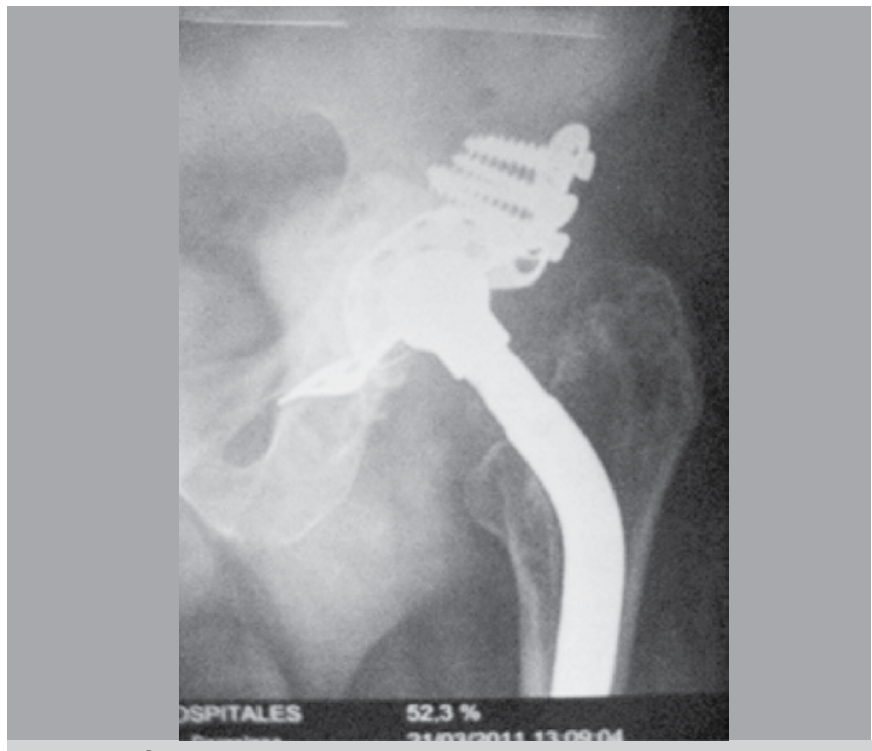

Figure 3. Stable fixation 4 years follow-up of a revision THA in defect Paprosky type $3 \mathrm{~B}$.

degree of bone loss based on radiographic parameters to guide the identification of reconstructive options.

In four patients of our series, we could see a dislocation of the prosthesis. This happened at the beginning of the cases. All were resolved without the need for new surgeries. These dislocations made us think that the use of a hip stabilizing orthosis in abduction would be appropriate. For this reason, we have used this type of orthosis for three months after the operation. This prevented new dislocations. In grade III Paprosky acetabular defects the first major problem we face is the loss of bone stock that exists and therefore we have to get an acetabular regeneration. Some authors when faced with loosening and significant bone loss ${ }^{10,11,12,13}$ have chosen to use a cemented cup of the next larger size and fill the defect with cement. This approach is still used despite Sofcot 1988 report $^{14}$ that highlighted a repeated rate of $33.3 \%$ of loosening with this technique and potential rate of $25 \%$ at 5 years detachment. These data support the need to rebuild and restore acetabular bone stock in revision arthroplasty by placing bone graft. Many surgeons have used the structural allograft in 
combination with a cemented cup, without using a reinforcing ring or without cemented cup..$^{15,16,17,18,19,20}$ After promising initial results, ${ }^{15}$ was reported failures after 5 years ${ }^{21}$ (20\% rate of loosening), 10 years ${ }^{22}$ (loosening rate $47 \%$ ) and then at $16^{23}$ (66\% rate of loosening). Nowadays, the morselized frozen allograft is giving excellent results. Graft incorporation occurs in two phases: initial phase with partial resorption of the graft and repopulation phase where new bone is formed in the graft host. 19,20,24,25 The incorporation of frozen morselized allografts has been verified in animals ${ }^{26,27}$ and confirmed in vivo. ${ }^{28,29}$ The use of isolated bone graft when faced with significant bone loss does not solve the associated problems such as mechanical stability and integration of the graft. Therefore, it seems appropriate to use a metal protective ring to stabilize these allografts and improve integration. There are two types of metal reinforcing rings: one type only provides a proximal fyxing (Müller ring type) and the other provides dual fixing through a hook (Ganz ring, cross Kerboull) or screw (BSAC). Some authors believe that the use of proximal fixation alone is not enough and that many of the failures can be attributed to the lack of primary stability. ${ }^{1,30}$ Gerber et al. ${ }^{31}$ adds that most failures occurred due to lack of primary stability of the ring, which led to graft lysis after loosening. For that reason in our series we have always resorted to using BSAC ring with good results.

There are many advantages with the combination of a reinforcement ring with a graft. First, the center of rotation of the hip is more likely to be restored ${ }^{31,32,33,34}$ which avoids the "high" center of rotation of the hip advocated by some surgeons.

We have managed to restore the center of rotation of the hip in all cases with the technique used. However, the elevation of the center of rotation is an acceptable alternative if several conditions are met: limited bone defects, without combined effect of rotation center. Second, the graft is protected and stabilized, which is essential for the integration of the graft. ${ }^{30,31}$ Few studies have compared the use of different reinforced rings. Bonnomet et al. ${ }^{32}$ found the ring BSAC to be better than the Muller ring in loosening cases with severe bone loss. Our series with a minimum follow-up of 4 years confirmed the good long-term results described in other published studies. 1,3,35,36,37,38,39 Patients who have Paprosky grade 3 acetabular defects are in a very unfavorable clinical situation with great functional limitations. The clinical results achieved at follow-up demonstrated a marked improvement (Figure 4). These patients would be, in case of don't realise this surgery, candidates to a Girdlestone resection arthroplasty. Radiological evaluation of bone graft resorption is difficult after using allograft bone impacted with cement and metal rings with an acetabular revision, but the stability of cemented cup gives us an important tranquillity. In most cases there is a uniformity of

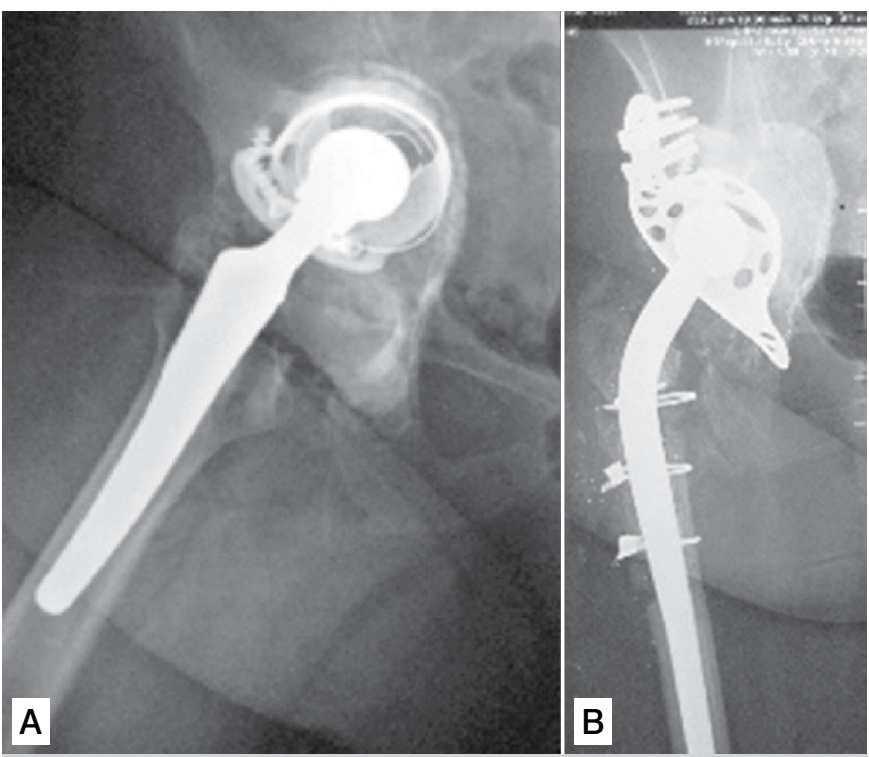

Figure 4. A) Preoperative acetabular defect paprosky type 3 B. B) Five years follow-up acetabular reconstruction.

the graft. But be cautious, because the results may deteriorate beyond 10 years. Allografts have been known resorptions later (after 10 years), therefore we must continue to monitor the long term this type of reconstruction. ${ }^{37}$

Radiological evaluation of bone graft absorption is difficult after using allograft bone impacted with cement and metal rings in an acetabular revision, but the stability of cemented cup gives us an important tranquillity. In most cases there is a uniformity of the graft. But it's important to be cautious, because the results may deteriorate beyond 10 years. When allografts, it has been known absorptions later (after 10 years), therefore we must continue controlling long term this type of reconstruction. ${ }^{37}$

\section{CONCLUSION}

Our study confirms the efficacy of using a frozen morselized allograft combined with a metal ring type BSAC during acetabular reconstruction. It is necessary to recover the center of rotation of the hip on its anatomical location for long term success. In massive loosening cases, the anatomical center of rotation can only be restored by the reconstruction of bone density using a graft protected by a ring which improves the centring of the head.

AUTHORS' CONTRIBUTIONS: All authors contributed individually and significantly to the development of this work. JJMC (0000-0003-1790-3241)*: wrote and reviewed the manuscript, performed the surgeries, and contributed to the intellectual conceptualization of the study and the entire research project; LG: performed the surgeries and data analysis, and wrote the manuscript; and APP: participated in the surgeries; reviewed, drafted, and reviewed the manuscript ${ }^{\star} \mathrm{ORCID}$ (Open Researcher and Contributor ID).

\section{REFERENCES}

1. Hansen E, Shearer D, Ries MD. Does a Cemented Cage Improve Revision THA for Severe Acetabular Defects? Clin Orthop Relat Res. 2011;469(2):494-502.

2. Charnley J. Low friction arthroplasty of the hip: theory and practice. Berlim Springer Verlag; 1979.

3. Regis D, Sandri A, Bonetti I. Acetabular Reconstruction with the Burch-Schneide Antiprotrusio Cage and Bulk Allografts: Minimum 10-Year Follow-Up Results. Biomed Res Int. 2014; 2014:194076.

4. Taylor ED, Browne JA. Reconstruction options for acetabular revision. World J Orthop. 2012;3(7):95-100.

5. Paprosky WG, Perona PG, Lawrence JM. Acetabular defect classification and surgical reconstruction in revision arthroplasty. A 6-year follow-up evaluation. J Arthroplasty. 1994;9(1):33-44
6. Comba F, Buttaro M, Pusso R, Piccaluga F. Acetabular reconstruction with impacted bone allografts and cemented acetabular components: a 2- to 13-year follow-up study of 142 aseptic revisions. J Bone Joint Surg Br. 2006;88(7) 865-9.

7. Schreurs BW, Slooff TJ, Gardeniers JW, Buma P. Acetabular reconstruction with bone impaction grafting and a cemented cup: 20 years $\square$ experience. Clin Orthop Relat Res. 2001;(393):202-15.

8. DeLee JG, Charnley J. Radiological demarcation of cemented sockets in total hip replacement. Clin Orthop Relat Res. 1976;(121):20-32.

9. D'Antonio JA, Capello WN, Borden LS, Bargar WL, Bierbaum BF, Boettcher WG, et al. Classification and management of acetabular abnormalities in total hip arthroplasty. Clin Orthop and Relat Res. 1989;(243):126-37.

10. Ash SA, Callaghan JJ, Johnston RC. Revision total hip arthroplasty with 
cement after cup arthroplasty long-term follow-up. J Bone Joint Surg Am. 1996;78(1):87-93.

11. Callaghan JJ, Salvetti EA, Pellici PM, Wilson PD Jr., Ranawat CS. Result of revision for mechanical failure after cemented total hip replacement, 1979 to 1982: a two to five year follow-up. J Bone Joint Surg Am. 1985;67(7): 1074-85.

12. Echeverri A, Shelley P, Wroblewski BM. Long term result of hip arthroplasty for failure of previous surgery. J Bone Joint Surg Br. 1988;70(1):49-51.

13. Pellici PM, Wilson PD Jr, Sledge CB, Salvati EA, Ranawat CS, Poss R, et al. Long term result of revision total hip eplacement: a follow-up report. J Bone Joint Surg Am. 1985;67(4):513-6.

14. Kavanagh BF, Fitzgerald RH Jr. Multiple revision for failed total hip arthroplasties non-associated with infection. J Bone Joint Surg Am. 1987;69(8):1144-9.

15. Harris WH, Crothers $\mathrm{O}$, Oh I. Total hip replacement and femoral head bone grafting for severe acetabular deficiency in adults. J Bone Joint Surg Am. 1977;59(6):752-9.

16. Tian JL, Sun L, Hu RY, Tian XB. Cementless total hip arthroplasty with structural allograft for massive acetabular defect in hip revision. Chin J Traumatol. 2014;17(6):331-4.

17. Sakellariou VI, Babis GC. Management bone loss of the proximal femur in revision hip arthroplasty: Update on reconstructive options. World J Orthop. 2014;5(5):614-22.

18. Vulcano E, Murena L, Falvo DA, Baj A, Toniolo A, Cherubino P. Bone marrow aspirate and bone allograft to treat acetabular bone defects in revision total hip arthroplasty: preliminary report. Eur Rev Med Pharmacol Sci. 2013;17(16):2240-9.

19. Lomas R, Chandrasekar A, Board TN. Bone allograft in the U.K. perceptions and realities. Hip Int. 2013;23(5):427-33.

20. Wimmer MD, Randau TM, Deml MC, Ascherl R, Nöth U, Forst R, et al. Impaction grafting in the femur in cementless modular revision total hip arthroplasty: a descriptive outcome analysis of 243 cases with the MRP-TITAN revision implant. BMC Musculoskelet Disord. 2013;14:19.

21. Gerber SD, Harris WH. Femoral head auto grafting to augment acetabular deficiency in patient requiring total hip replacement. J Bone Joint Surg Am. 1986;68(8): 1241-8

22. Kwong LM, Jasty M, Harris WH. High failure rate of bulk femoral head allografts in total hip acetabular reconstruction at 10 years. J Arthroplasty. 1993;8(4):341-6.

23. Shinar AA, Harris WH. Bulk structural autogenous grafts and allografts for reconstruction of the acetabulum in total hip arthroplasty. J Bone Joint Surg Am. 1997;79(2): 159-68.

24. Burchardt $\mathrm{H}$. The biology of bone graft repair. Clin Orthop Relat Res. 1983;(174):28-42.

25. Goldberg VM, Stevenson S. Natural histology of autografts and allografts. Clin Orthop Relat Res. 1987;(225):7-16.
26. Lamerigts NM, Buma P, Aspenberg P, Schreurs BW, Slooff TJ. Role of the growth factors in the incorporation of unloaded bone allografts in the coat. Clin Orthop Relat Res. 1999;(368):260-70.

27. Van Loon CJM, Malefiijt MCW, Buma P, Stolk T, Verdonschot N, Tromp AM, et al. Autologous morsellised bone grafting restores uncontained femoral bone defects in knee arthroplasty: an in vivo study in horses. J Bone Joint Surg Br. 2000;82(3):436-44.

28. Piert M, Zittel TT, Machulla HJ, Becker GA, Jahn M, Maier G, et al. Blood flow measurements with [15 $\mathrm{O}] \mathrm{H} 2 \mathrm{O}$ and [18F]fluoride ion PET in porcine vertebrae. J Bone Miner Res. 1998;13(8):1328-36.

29. Piert M, Winter E, Becker GA, Bilger K, Machulla H, Muller-Schauenburg W, et al. Allogenic bone graft viability after hip revision arthroplasty by dynamic [18 F] fluoride ion positron emission tomography. Eur J Nucl Med. 1999;26(6):615-24.

30. Kerboull M, Hammadouche M, Kerboull L. The Kerboull acetabular reinforcement device in major acetabular reconstruction. Clin Orthop Relat Res. 2000;(378): 155-68

31. Gerber A, Pisan M, Zurakowski D, Isler B. Ganz reinforcement ring for reconstruction of the acetabular defects in revision total hip arthroplasty. J Bone Joint Surg Am. 2003;85-A(12):2358-64.

32. Bonnomet F, Clavert P, Gicquel P, Lefebvre J, Kempf JF. [Reconstruction by graft and reinforcement device in severe aseptic acetabular loosening: 10 years survivorship analysis.] Rev Chir Orthop Reparatrice Appar Mot. 2001;87(2):135-46.

33. Morand F, Clarac JP, Gayet LE, Pries P. [Acetabular reconstruction using bone allograft in the revision of total hip prosthesis]. Rev Chir Orthop Reparatrice Appar Mot. 1998;84(2):154-61.

34. Peters C, Curtain M, Samuelson KM. Acetabular revision with the Burch-schneider antiprotrusio cage and cancellous allograft bone. J Arthroplasty. 1995;10(3):307-12.

35. Parratte S, Argenson JN, Flecher X, Aubaniac JM. [Acetabular revision for aseptic loosening in total hip arthroplasty using cementless cup and impacted morselized allograft]. Rev Chir Orthop Reparatrice Appar Mot. 2007;93(3):255-63.

36. Emms NW, Buckley SC, Stockley I, Hamer AJ, Kerry RM. Mid- to long-term results of irradiated allograft in acetabular reconstruction: a follow-up report. J Bone Joint Surg Br. 2009;91(11):1419-23.

37. Buckup J, Salinas EA, Valle AGD, Boettner F. Treatment of Large Acetabular Defects: A Surgical Technique Utilizing Impaction Grafting into a Metallic Mesh. HSS J. 2013;9(3):242-6.

38. Garcia-Cimbrelo E, Cruz-Pardos A, Garcia-Rey E, Ortega-Chamarro J. The Survival and Fate of Acetabular Reconstruction With Impaction Grafting for Large Defects. Clin Orthop Relat Res. 2010;468(12):3304-13.

39. Sembrano JN, Cheng EY. Acetabular Cage Survival and Analysis of Factors Related to Failure. Clin Orthop Relat Res. 2008;466(7):1657-65. 